\title{
Analysis on the Implementation, Gains and Losses of the Writing System of Bouyei Nationality - Taking Bouyei Nationality in Liuzhi Special District, Guizhou Province as an Example
}

\author{
Linglv Wang ${ }^{1, *}$ \\ ${ }^{1}$ School of Literature, Jinan University, Guangzhou, Guangdong, China \\ *Corresponding author.Email: wangllv@stu2019.jnu.edu.cn
}

\begin{abstract}
Through long-term communication and exchanges, various ethnic groups in China have established relatively harmonious ethnic relations. After the founding of new China, the government carried out ethnic identification and local self-government for all ethnic groups in the territory. And then, the work of creating characters for ethnic minorities started. Since the introduction of the writing system of Bouyei nationality in the 1950s, with the support of national policies, the cultural education of the Bouyei nationality in Guizhou Province has achieved certain results. However, due to the constraints of historical and practical factors, the promotion of the writing system of Bouyei nationality has made tortuous progress. Among them, the promotion in Liuzhi Special District eventually failed, and the characters of Bouyei nationality gradually disappeared from the ethnic education in the classroom.
\end{abstract}

Keywords: Bouyei nationality, Ethnic minorities, Writing system, Ethnic integration.

\section{INTRODUCTION}

As one of the ethnic groups with a population of one million people in China, the Bouyei nationality has a long history and has its own unique traditional customs and ethnic culture. The Bouyei language belongs to the Zhuang-Dong language family in the Sino-Tibetan language family, but the Bouyei nationality does not have its own characters. At the beginning of the founding of new China, in order to preserve national culture and promote national integration, the state organized various forces to formulate writing systems for ethnic minorities based on the principles of ethnic equality and unity. In the early $1950 \mathrm{~s}$, characters were created for more than a dozen ethnic groups such as Zhuang nationality, Miao nationality, Bouyei nationality, and Dong nationality, and they were promoted and used simultaneously. In the 1960s and 1970s, the writing systems of other ethnic minorities were launched one after another until the end of the 1990s.
The writing system of Bouyei nationality in Liuzhi Special District once achieved good results since it was launched and implemented. However, it has gradually declined after the 1990s, especially since entering the 21 st century, bilingual teaching has gradually withdrawn from the classroom, and the promotion of Bouyei scripts in Liuzhi has gradually disappeared from the historical stage. From the very beginning, the writing system of Bouyei nationality was implemented to allow more Bouyei people to understand and learn from their own national culture, but this program has achieved limited results. As early as in the 1980s, due to insufficient efforts, good opportunities were missed, and when people entered the new era, the writing system of Bouyei nationality continued to be implemented in Liuzhi Special District as if it was incompatible with the trend of the times. 


\section{THE CREATION AND PROMOTION OF THE WRITING SYSTEM OF BOUYEI NATIONALITY}

The Bouyei nationality is a branch of the ancient "Baiyue" people. As early as in the pre-Qin period, they had already lived in Guizhou. According to the fifth census, the population of Bouyei nationality in Guizhou Province accounts for $97 \%$ of the total population of Bouyei nationality in the country. The Bouyei people are mainly distributed in Guizhou, but also sporadically distributed in Yunnan and Sichuan. The Bouyei people in Guizhou can be divided into three areas based on geographical separation, some customs and cultural differences.

After the founding of new China, in order to solve the historically difficult and complicated ethnic relationship among the ethnic minorities in China, the party and the government carried out ethnic identification, finally confirming that there are 56 ethnic groups in China. [1] On this basis, local ethnic autonomous administrative units were established in accordance with the distribution of ethnic minority settlements. By 1990, 53 ethnic autonomous areas were successively established across the country.

Ethnic identification and regional autonomy of ethnic minorities are the cornerstones of the creation of writing system of ethnic minorities in China. Beginning in the 1950 s, in order to promote national unity and achieve national prosperity, the party and government decided to create national scripts for all ethnic minorities in China. The writing system of Bouyei nationality was proposed and created under this historical background.

In 1956, the investigation team of the Chinese Academy of Sciences selected 40 settlements of the Bouyei ethnic group in Guizhou as the survey objects. After comparing them with the Zhuang language that is closely related to the same language family, they believed that although there were differences in tone and intonation within the Bouyei ethnic group due to regions, customs and some vocabularies, they are generally the same without dialect distinctions. And only one type of script is created (in contrast, the Miao nationality creates four scripts due to the huge differences in language). In order to promote cultural exchanges and mutual development between the Bouyei nationality and Zhuang nationality, the investigation team held a special seminar in
Guiyang in November 1956, namely, the "Scientific Symposium on Bouyei Language and Writing". And the "Bouyei Writing System (Draft)" was issued. This draft is based on the Latin alphabet, and the dialect of Yangchang Town (belonging to the second native area in which Bouyei language is used) in Longli County is regarded as the reference language. [2] The writing system was approved by the Central Ethnic Affairs Commission and has been carried out in the areas for Bouyei nationality since 1957. In 1958, the writing system of Bouyei nationality was temporarily suspended due to the "Great Leap Forward" and the "Left-leaning thought at that time, and the development of ethnic minorities' work was restricted. After the 1980s, with the nationwide efforts to correct chaos, the promotion of the writing system of Bouyei nationality was once again on the agenda. In 1981, with the new investigation, a group of experts in the province held several seminars and decided to abandon the previous Bouyei-Zhuang script alliance plan, re-modified the writing system of Bouyei nationality, and passed the "Revision for the writing system of Bouyei nationality (Draft)". This plan took the dialect of Fuxing Town in Wangmo County as the reference language, and the Latin alphabet was still used as the text. After reviewing this plan, the Guizhou Provincial Ethnic Education Commission decided to implement it in the pilot. These locations (settlements) include Fuxing Town in Wangmo County, Luodian Commune in Luodian County, Dafang in Longli County, and Dazhai Brigade in Huaxi District, Guiyang City. [3] After summing up the experience of the pilot implementation, in March 1985, the Guizhou Provincial Ethnic Education Committee held a symposium again to further improve and modify the writing system of Bouyei nationality and promote it to the settlements of Bouyei nationality throughout the province.

Since 1985, the writing system of Bouyei nationality has been promoted in Liuzhi Special District. Luobie Township, Mugang Town and other places took the lead in teaching Bouyei language in classrooms. There are several ways to promote the writing system of Bouyei nationality. First, it is used in bilingual education in primary schools. The level of educational development in ethnic minority areas is low. Most children learn Pinyin and Chinese characters first, and then use these two media to learn the Bouyei script; but in some areas, children learn the ethnic language first and then learn Chinese. The second, it is used to eliminate illiteracy among adults. For the Bouyei 
people in Liuzhi Special Economic Zone who use less Chinese, thanks to their daily language habits, eliminating illiteracy with the use of the Bouyei language is much simpler and more effective than that with Chinese. The third is the promotion in the field of radio and television. Since the 1990s, with the gradual popularization of information technology media, the number of local TV dramas and dances produced in the Bouyei language and scripts has also increased, and the Bouyei people have also learned the Bouyei language. Since its pilot experiment in Liuzhi Special District, the writing system of Bouyei system has helped many Bouyei people improve their cultural literacy, and it has also promoted economic development and tourism development in the area for the Bouyei nationality. However, due to the relatively low cultural level of the Bouyei ethnic group in history, the promotion of writing system has been greatly restricted. The most suitable audiences for the promotion of Bouyei language are the students of elementary schools, and the senior students no longer learn Bouyei language due to their academic needs. In addition, adults do not have the time and occasion to learn, so the writing system did not achieve the expected results.

\section{REASONS FOR THE FAILURE OF THE WRITING SYSTEM OF BOUYEI NATIONALITY IN LIUZHI SPECIAL DISTRICT}

\subsection{Geographical, Cultural and Customary Factors}

Liuzhi Special District is located in the west of Guizhou Province, on the Yunnan-Guizhou Plateau. The landform is mainly composed of mountains and valleys, with the characteristics of terrain disparity, strong cutting, and large fluctuations. [4] This natural geographical situation determined the difficulties in the transportation of Liuzhi Special District in the past, and it was difficult to communicate with the outside world. The internal agricultural production and life were generally backward, and the level of culture and education was generally low.

The settlements of Bouyei ethnic group in Guizhou can be divided into three areas based on regional and phonetic differences. However, the state only created one language of the Bouyei ethnic group. Among the three native languages, the pronunciations of the first and second native languages are relatively close, accounting for about
$80 \%$ of the total number of Bouyei people. The phonetic difference between the third dialect and the first dialect is relatively large, accounting about $20 \%$ of the total number of Bouyei people. There are only more than 45,000 Bouyei people in Liuzhi Special Economic Zone, accounting for less than $2 \%$ of the total ethnic population. They are linguistically biased towards the third dialect (some of them belong to the area in which the second dialect is used). [5] The two writing systems of Bouyei nationality that have been promoted are based on the first and second native languages, which makes it more difficult for the Bouyei people in Liuzhi Special District who are accustomed to using the third native language to learn the Bouyei script.

Since the 1950s, there are three types of writing system promotion. The "Bouyei-Zhuang Language Alliance" in the 1950s was a program closer to Pinyin of Han nationality. Among them, the same and similar sounds in Bouyei language and Chinese should be represented by the equivalent letters in the "Pinyin" as much as possible, while the sounds that are not in Chinese should be represented by new letters or double letters as appropriate. Therefore, the spelling of text syllables in this program is relatively short, the longest syllable has only 5 letters, and the phonetic function is relatively accurate. Later, the Bouyei people in Guizhou Province wanted to use their own language instead of sharing the same writing system with the Zhuang nationality. Therefore, this writing system was not reintroduced in the 1980s. The two programs improved and implemented in the 1980s all adopted 26 Latin letters as the form. The text was more verbose and cumbersome. The longest syllable was composed of 8 letters, such as "ngvoangh" (aging). In the first edition, the "guagb" (aging) has five letters. At the same time, learning the Bouyei script also requires the correct correspondence between the text and the voice. Since Liuzhi Special District is located in the area in which the third native dialect is used, there are also phonetic differences from the first native dialect. For example, "genal" (to eat) in the third native language is pronounced "geenl" in the first native language. In terms of the differences in pronunciation and glyphs, if the Bouyei people in the Liuzhi Special District want to learn the Bouyei script, they must overcome the difficulties of learning Chinese and the phonetic differences within the nationality. If they don't make changes, it will lead to inaccurate pronunciation and self-defeating and undoubtedly increase the difficulty of learning. In addition, there 
are two challenges in bilingual teaching. First, Bouyei people who do not speak and write Chinese find it difficult to learn the Bouyei language through Chinese, and those who are proficient in and use Chinese are not interested in Bouyei language.

\subsection{Economic and Educational Factors}

The economic and cultural backwardness of Guizhou is also an important factor that makes the promotion of the writing system of Bouyei nationality difficult to achieve success. In the past, Guizhou's economic and production sectors were dominated by agriculture, social and economic production was backward, and the level of cultural education was not high. Since the implementation of the first five-year plan in the 1950s, the government has carried out industrial construction

Table 1. Average annual GDP growth rate and ranking of ethnic minority areas

\begin{tabular}{|c|c|c|c|c|c|c|}
\hline \multirow[t]{2}{*}{ Area } & \multicolumn{2}{|c|}{$1952 \sim 1978$} & \multicolumn{2}{|c|}{$1978 \sim 1990$} & \multicolumn{2}{|c|}{$1990 \sim 1999$} \\
\hline & Growth Rate & Ranking & Growth Rate & Ranking & Growth Rate & Ranking \\
\hline Ethnic minority agglomeration & 5.7 & 16 & 8.4 & 15 & 9.6 & 22 \\
\hline Guizhou province & 4.6 & 26 & 8.3 & 12 & 8.7 & 27 \\
\hline Yunnan province & 6.0 & 9 & 9.3 & 8 & 9.3 & 23 \\
\hline Guangxi province & 4.9 & 25 & 7.2 & 25 & 12.1 & 11 \\
\hline Ningxia province & 6.2 & 8 & 8.2 & 13 & 8.4 & 29 \\
\hline Xinjiang province & 5.8 & 10 & 9.9 & 7 & 9.9 & 20 \\
\hline Areas for the Han nationality in interior & 6.1 & & 8.6 & & 12.1 & \\
\hline The whole area of China & 6.3 & & 8.4 & & 12.2 & \\
\hline
\end{tabular}

a Source: Wen Jun. "Nation and Development: New Modernization Strategy for the Catch-up", Beijing: Tsinghua University Press, 2004, p.156.

As far as the allocation of education funds is concerned, the Liuzhi Special Zone has also invested relatively little during the period of promoting the writing system of Bouyei nationality. From 1980 to 1995 , Liuzhi Special District invested only 255,300 yuan in education, culture, and health subsidies in ethnic minority towns (including 105,000 yuan in education subsidies for poor students). [5] In addition, the main body of cultural education of ethnic minority in Guizhou is teachers of Han nationality. The minority teachers are small in number. Also, there are problems in the structure. The economy of ethnic minority areas is relatively backward, and few teachers are willing to go. Local governments can only rely on national special post teachers and support staff. The number of minority teachers in Guizhou is small, the educational level of the staff is also relatively low, and the number of teachers with undergraduates in the southwestern ethnic regions, but there is still a big gap between the development of Guizhou and the eastern coastal areas. From the data in "Table $1 "$, it can be clearly seen that during the three periods from 1952 to 1999, the GDP (Gross Domestic Product) growth ranking of Guizhou was once accelerated by the investment of the state. However, with the reform and opening up, it was impacted by the market economy and slowed down. At the same time, Guizhou vigorously develops heavy industry because of its rich mineral resources. It is precisely because of the emphasis on the development of the secondary industry that the emphasis on the tertiary industry and cultural undertakings is not high. As a result, the development of cultural and educational undertakings and national cultural industries in the Special District is relatively low. and above is relatively small. In the past, the majority of teachers in ethnic villages and towns had high school and junior college diplomas. Teachers who were exposed to the Bouyei language in the 1980s have basically retired. Since the 1990s, as bilingual teaching has gradually withdrawn from the classroom, minority languages and scripts are no longer taught in ethnic schools. This situation is also related to higher education and examinations. It is true that the purpose of bilingual teaching is to preserve the national culture while children of Bouyei nationality learn Chinese; however, as students age, bilingual teaching is no longer applicable, and Chinese becomes more dominant. The admissions and examinations do not rely on the writing system of Bouyei nationality. The students of Bouyei nationality may find it new to learn the Bouyei language at the beginning, but they tend to 
feel boring in the process of using it, and in the end they reduce or even no longer use it.

In the new era, China's economic development has obtained world-renowned achievements, and China has become the second largest economy worldwide. Thanks to the development of the economy, the abundance of teaching methods and the support of national policies, ethnic education in Guizhou has also been adequately developed. However, it needs to be clearly recognized that due to the late historical development and geographical factors, the economy of ethnic minority areas is not very developed. The gap between the education investment in Guizhou and the eastern provinces is still very obvious. This gap will continue to expand with the deepening of the market economy. With the superior economic conditions in the east, more talents from the west will go the east, forming a vicious circle. In order to change this situation, China has vigorously developed the western region and achieved good results. However, the longstanding reality of poverty and low education in Guizhou is difficult to completely change overnight, and it will take time.

\subsection{The Impact of Culture in the New Era}

According to the Marxist ethnology theory, it is believed that the "ethnic process" is a historical process that every nation in the world has to go through. Researchers have different expressions on what content should be included in the ethnic process. However, viewing the ethnic process as the formation, development, integration, and extinction of a nation is the most general overview in academia. Hao Shiyuan believes: "The ethnic process, as an organic and regular movement of human society, is the process of the movement of the national community from a lower level to a higher level. [5] The lower stage gives birth to the higher stage. Nations develop in formation, fuse in development, and die in fusion." Under the impact of the market economy and culture in the new era, the phenomenon of national integration and extinction is more prominent and common.

The Bouyei people in Liuzhi Special Economic District have lived in deep mountains and forests for generations. Due to terrain barriers and backward transportation, it is difficult to contact with the outside world. Since the 1980s, with the vitality of the Chinese market, the economic development and attractiveness of employment in the east, more and more Bouyei people go to the east. Bouyei people who left the western region broke away from the environment of the Bouyei people they were accustomed to. When they went to other places, they mainly spoke Chinese whether they were communicating with the Han nationality or other ethnic minorities. In studying and working, most of them have contact with the Han nationality, and it is necessary to use Chinese. In contrast, the Bouyei language and characters are only used in very few occasions. In this situation, it is of little significance for Bouyei families who have moved or migrated to learn the Bouyei script. From "Table $2 ",[6]$ the main factors for the migration of some ethnic minorities to other places in China include employment, business and job transfer, and learning and training also account for a large proportion. In general, these three factors are all involved in economic and cultural development.

Table 2. Reasons for migration of some ethnic minorities in China

\begin{tabular}{|l|l|l|l|l|l|l|l|l|l|}
\hline Nationality & $\begin{array}{l}\text { Proportion } \\
\text { of migrant } \\
\text { population } \\
\text { to total } \\
\text { population }\end{array}$ & $\begin{array}{l}\text { Being } \\
\text { engaged in } \\
\text { industry or } \\
\text { business }\end{array}$ & $\begin{array}{l}\text { Job } \\
\text { transfer }\end{array}$ & Employment & $\begin{array}{l}\text { Training } \\
\text { and } \\
\text { learning }\end{array}$ & $\begin{array}{l}\text { Demolition } \\
\text { and } \\
\text { relocation }\end{array}$ & Marriage & $\begin{array}{l}\text { Seeking } \\
\text { refuge } \\
\text { with } \\
\text { relatives }\end{array}$ \\
\hline $\begin{array}{l}\text { Han } \\
\text { nationality }\end{array}$ & 10.76 & 31.25 & 4.25 & 3.05 & 11.53 & 14.75 & 11.58 & 12.72 & 4.98 \\
\hline $\begin{array}{l}\text { Zhuang } \\
\text { nationality }\end{array}$ & 9.54 & 39.10 & 5.06 & 3.99 & 10.98 & 5.39 & 13.86 & 12.20 & 4.50 \\
\hline $\begin{array}{l}\text { Bouyei } \\
\text { nationality }\end{array}$ & 6.80 & 26.25 & 3.89 & 3.81 & 12.20 & 5.56 & 28.64 & 11.29 & 3.89 \\
\hline $\begin{array}{l}\text { Tibetan } \\
\text { nationality }\end{array}$ & 4.43 & 9.97 & 9.72 & 8.45 & 20.95 & 6.09 & 16.26 & 12.25 & 6.43 \\
\hline $\begin{array}{l}\text { Miao } \\
\text { nationality }\end{array}$ & 7.48 & 32.16 & 4.30 & 3.14 & 10.38 & 4.47 & 24.15 & 12.37 & 4.06 \\
\hline
\end{tabular}

a Source: Population and Social Science and Technology Department of National Statistics Bureau, Economic Development Department of National Ethnic Education Commission,

Since the reform and opening up, the eastern region has been relying on superior geographical conditions and markets to increase its external contacts, and the economic and market benefits 
have fully manifested. The gap between the western region and the eastern region has gradually widened in terms of economic and cultural development, and the population has also flowed to the eastern region. In the context of the globalization, any nation can no longer "pay attention to one's own moral uplift without thought of others" and live a "poverty and happy" life. Whether it wants to or not, it will be involved in the vortex of contact and exchange with other nations. Economic globalization brings cultural globalization at the same time. Cultural globalization has brought progress to the world, enabling peoples in different regions of the world to share cultural feasts and participate in cultural creation. However, cultural globalization also brings unfair and unbalanced cultural competition. At the same time, within a country, the language and culture of dominant ethnic groups will unconsciously compress and squeeze the living space of ethnic minority cultures. Although China is a big ethnic family composed of 56 ethnic groups, unlike the ethnic minorities in other multiethnic countries such as Russia, China's ethnic minorities are sparsely populated. Among the 56 ethnic groups, the population of Han nationality accounts for $90 \%$ of the total population, and the population of remaining 55 ethnic minorities accounts for only about $10 \%$. Culturally, the strong position of Chinese has been unshakable for thousands of years, and this trend has deepened since entering the modern era. With the cessation of the use of Zhuang scripts and the disappearance of four types of Miao scripts, the disappearance of other minority scripts such as Bouyei scripts has become increasingly obvious.

Since the beginning of the new century, due to the convenience of transportation and economic development, the Bouyei people have abandoned the traditional concept of staying behind in the wave of global changes, stepped out of the ethnic regions, and continued to march to the eastern cities and even other countries and regions in the world. With the convenience of Mandarin and the charm of Chinese, more ethnic minorities study the Chinese continuously. In contrast, the relatively obscure and incomprehensible culture of ethnic minorities makes more and more ethnic minorities resist. And even, they are unwilling to express their national identities. Among the Bouyei people, this kind of thinking is extremely common, and more and more Bouyei families cannot speak the dialect or use the script.

\section{CONCLUSION}

China's national education aims to realize the great rejuvenation of the Chinese nation by protecting and inheriting the excellent traditional national culture. The creation and implementation of ethnic minority scripts in China has a history of more than 60 years. In more than half a century of development, some ethnic scripts have been ceased, and some are still struggling. This article attempts to explore the pros and cons of the writing system of Bouyei nationality in Liuzhi Special Economic District, as well as the declining factors, and also makes the reflection on the ethnic education work in the future. The development of modern economy and cultural impact are the most direct factors hindering the continued implementation of the writing system of Bouyei nationality; the backward economy of Liuzhi Special District, the weak cultural and educational foundation, the insufficient investment in education, and the scarcity of teacher resources make the promotion of the writing system of Bouyei nationality difficult. In addition, the conservative traditional ideas of the Bouyei people have also been shattered with the impact of globalization. The idea of learning Chinese, going to the world, and reducing or even abandoning the use of the Bouyei language has become increasingly popular among the Bouyei people in Liuzhi Special Economic District. This is the result of ethnic integration and a contradiction that ethnic educators will strive to resolve. The ethnic educators need to think about how to protect and promote excellent ethnic minority culture in a world where modern cultures are increasingly integrated, and how to educate the next generation to love and inherit the national spirit. The national education work is still on the way, far from over.

\section{AUTHORS' CONTRIBUTIONS}

This paper is independently completed by Linglv Wang.

\section{REFERENCES}

[1] Wang Wei, Li Dengfu, Chen Xiuying. "Bouyei People", Beijing: Nationalities Publishing House, 1991. (in Chinese)

[2] Wang Hongman. "Introduction to New China's Ethnic Policy", Beijing: Minzu University of China Press, 2000. (in Chinese)

[3] Zhou Qingshen: "Comparison of the Creation of Minority Languages in the Early Days of 
the Founding of China and Soviet Union", National Languages, Issue 6, 2002. (in Chinese)

[4] Tian Fengchun. "The Pilot Work of Bouyei Ethnic Languages", "Guizhou Ethnic Studies", Issue 5, 1982. (in Chinese)

[5] Liuzhi Special District Local Chronicles Compilation Committee. "Liuzhi Special District Chronicles", Guiyang: Guizhou People's Publishing House, 2002. (in Chinese)

[6] Zhou Zhengang. "Research on the Development of Minority Education in Guizhou", "Journal of Southwest University for Nationalities (Humanities and Social Sciences Edition)", Issue 4, 2015. (in Chinese) 